Editor: Dr Mark Levy

Editorial Board:

Dr Chris Griffiths

Dr John Haughney

Dr Robert McKinley

Dr Paul Stephenson

Statistical Adviser:

Prof Peter Kelly

International Editorial

Adviser:

Prof Onno van Schayck

Asthma in General Practice is published on behalf of the General Practitioners In Asthma Group (GPIAG) by:

Strategic Medical Publishing, Action International House, Crabtree Office Village,

Eversley Way, Thorpe,

Egham, Surrey TW20 8RY.

The GPIAG operates independently of any commercial company. However, it does receive an educational grant from Allen \& Hanburys Ltd, in order to finance the group's secretariat, its Annual Scientific Meeting, its Research Unit and this journal.

\section{ISSN 0968-039X}

Research Editor:

Christine Drewienkiewicz

Project Editor:

Jane Mortlock

The views expressed in this journal are not necessarily those of the General Practitioners In Asthma Group, the publisher or Allen \& Hanburys Ltd.

Editorial decisions are independent of commercial restraints.

(C) GPIAG Committee. All rights reserved. No part of this publication may be reproduced, stored in a retrieval system or transmitted, in any form or by any means, without the prio permission of the GPIAG Committee.

Correspondence concerning the journal should be addressed to the editor

This journal is sent to members of the GPIAG, UK primary care faculties and NHS postgraduate centres. It is available for subscription from the publishers, Strategic Medical Publishing Ltd.

For further information about the General Practitioners In Asthma Group write to:

GPIAG Secretariat, The Medical Marketing Interface, Bath Brewery, Toll Bridge Road, Bath BA1 7DE.
$\mathrm{T}$ wo current hot topics are discussed in detail in the review section of this issue. Professor Neil Thomson highlights the important issues related to inhaled topical steroids and their use in adult asthma. Evidence related to add-on therapy with long acting $\beta_{2}$-agonist bronchodilators, leucotriene antagonists or theophyllines enables the reader to choose between these options and identifies areas for further research.

Professor van Schayck et al, present evidence based recommendations for the management of COPD. This paper provides us with options and strategies for diagnosing and treating this prevalent condition. Our intention, in presenting these two papers, is to stimulate a lively discussion, through correspondence to the journal, on these two very topical issues.

The pilot study by Christopher Hand tackles the complexities related to high quality questionnaire development and implementation in order to improve our understanding of our patients beliefs related to inhaler treatment. This type of study is invaluable in our struggle against poor patient as well as health professional compliance.

David Price and colleagues have elegantly summarised the process and outcome of a public meeting to address issues related to people's beliefs on steroids.

It is evident that Asthma in General Practice is attracting a high quality of papers. We hope these papers stimulate our readers to think about their practice and would really value some feedback on the clinical practical value of the ideas and issues raised. Constructive criticism of papers published will further enhance the value of our journal. Please address any correspondence to The Editor and we will endeavour to publish this on our website soon, with selected correspondence published in the journal.

Finally, please let me remind you that we are currently calling for papers for our XIIth Annual Scientific Meeting on the 4th and 5th June 1999: deadline for abstracts is 31 January 1999. Please contact Strategic Medical Publishing for abstract forms and for more information about the ASM please contact the Secretariat, MMI.

\section{Mark Levy}

Editor

Review

\title{
What is the future for inhaled steroids in adult asthma care?
}

\section{N C Thomson}

I

nhaled steroids are the most effective, locally administered drugs available for chronic asthma. Patients with mild to severe asthma respond to inhaled steroids; demonstrating improved asthma symptoms and lung function as well as reduced bronchial reactivity and rates of exacerbation from asthma. ${ }^{1}$ The revised British Asthma Guidelines ${ }^{2}$ emphasise the importance of the early introduction of inhaled steroids as first-line therapy for those with mild disease (step 2) and of gaining rapid control of asthma by inhaled steroid therapy at a dose high enough to control the disease. High-dose inhaled steroids also have an important place in steps 3 to 5 . Although inhaled steroids have a central role in the management of adult asthma, a number of important issues remain unresolved about the most effective use of these drugs.

\section{DOSE-RESPONSE AND STEPPING DOWN}

Several studies have demonstrated a dose-response relationship as regards efficacy of inhaled steroid administered in doses of up to $800 \mu \mathrm{g}$ daily.,4 The therapeutic value of higher doses is less clearly established which is in part due to the poor design of some previous studies. Another important factor to consider when assessing dose-response studies of inhaled steroids is that the effect on one outcome measure (for example, PEF recording) may occur at a different dose to that for another outcome measure, such as inhibition of exercise-induced asthma. For many asthmatic patients a plateau in the therapeutic response to inhaled steroids occurs at doses below 1000 mcg daily, although some patients will benefit from higher doses. The task of predicting which patients with severe chronic asthma should receive high-dose inhaled steroid therapy is a difficult one. The value of non-invasive tests of airway inflammation such as induced sputum cell counts or exhaled nitric oxide in predicting the dose of inhaled steroid therapy appropriate for an individual patient has not been established. Currently a trial of high-dose inhaled steroids remains the only method of assessing clinical effectiveness

It may be possible to step down the inhaled steroid dose in a sizeable proportion of patients with chronic stable asthma who are receiving $\geq 1000 \mathrm{mcg}$ daily. Several shortterm studies suggest that many patients can achieve large reductions in inhaled steroid dosage without asthma control deteriorating. ${ }^{5-7}$ A major concern is whether the dose of inhaled steroid can be reduced in the long-term with the same effect. Furthermore, greater use of oral corticosteroids to treat exacerbations may override any attempt to minimise steroid-induced side-effects by the reduction of inhaled steroids. The recently published British Asthma Guidelines ${ }^{2}$ recommend that, providing the patient's asthma is stable, reductions should take place every one to three months; decreasing the dose of inhaled steroid by approximately $25-50 \%$ at each step. The criteria used to define asthma control both before and during steroid reduction are not well established. Further research is required to establish simple criteria to help identify those patients who can safely step down from high doses of inhaled steroids. 